\title{
Comunicación
}

\section{AISLAMIENTO DE Haemophilus parasuis EN PULMONES DE PORCINOS EN LIMA, PERÚ: REPORTE DE TRES CASOS}

\author{
Isolation of Haemophilus parasuis in Lungs of Pigs in Lima, Peru: A report \\ of Three Cases
}

\author{
Chris Pinto J. ${ }^{1}$, Sonia Calle E. ${ }^{1,2}$, Siever Morales C. ${ }^{1}$
}

\section{RESUMEN}

Se presentan tres casos ocurridos entre mayo y junio de 2006, en base a muestras de pulmón de cerdo procedentes de dos granjas de crianza porcina y de un camal de la zona de Lima. Los resultados del aislamiento y pruebas bioquímicas fueron compatibles con Haemophilus parasuis.

Palabras clave: Haemophilus parasuis, tracto respiratorio, porcino, morbilidad, mortalidad, aislamiento

\section{Abstract}

The paper document three cases occurred in May and June, 2006, based on lung samples from pigs of two farms and one slaughterhouse in Lima, Peru. The results of isolation and biochemical test were compatible with Haemophilus parasuis.

Key words: Haemophilus parasuis, respiratory tract, pig, morbility, mortality, isolation

Haemophilus parasuis es una bacteria potencialmente patógena que coloniza el tracto respiratorio superior del cerdo (Nielsen, 1993) y es causante de la "Enfermedad de Glässer" (Nedbalcova et al., 2006). Es un bacilo o cocobacilo pequeño, Gram negativo, inmóvil, aerobio y anaerobio facultativo. Además, es dependiente del factor V (nicotinamida adenina dinucleótido, NAD) para su crecimiento, por lo que debe ser cultivado en agares que incorporan sangre calentada (agar chocolate) con la adición directa de NAD

\footnotetext{
${ }^{1}$ Laboratorio de Microbiología y Parasitología Veterinaria, Facultad de Medicina Veterinaria, Universidad Nacional Mayor de San Marcos, Lima

2E-mail: calleson@gmail.com
} 
(0.025\%) o, en su reemplazo, ser cultivados con una estría de Staphylococcus aureus en el medio que le proporcionará el factor $\mathrm{V}$. Se han descrito 15 serotipos distintos de este agente, y existen también serotipos no tipificables (Rapp-Gabrielson y Gabrielson, 1992).

La enfermedad cursa con poliserositis y artritis (Rapp-Gabrielson y Gabrielson, 1992). Los cerdos infectados pueden desarrollar fiebre, neumonía y signos neurológicos, especialmente los jóvenes (Nielsen, 1993). El cerdo es el único hospedador de esta bacteria, que se transmite por contacto directo vía aerógena y puede infectar hasta el 75\% de los lechones destetados (Bilkei et al., 1995). Este agente forma parte del Complejo Respiratorio Porcino (Nedbalcova et al., 2006).

El cuadro clínico depende de la localización de las lesiones inflamatorias. Según esto, Hoeffling (1994) describe cuatro formas clínicas: la enfermedad de Glässer propiamente dicha o poliserositis fibrinosa, la septicemia (sin lesiones de poliserositis), la miositis aguda (en los músculos maseteros) y la enfermedad respiratoria. A la necropsia, se observa un exudado serofibrinoso o fibrinopurulento en las mucosas, de forma localizada o en presencia múltiple, incluyendo el peritoneo, pericardio y pleura. En los casos septicémicos se observa petequias y equimosis en hígado, riñón y meninges, y altos niveles de endotoxinas en el plasma, así como trombos de fibrina en muchos órganos (Amano et al., 1994). La inflamación de las meninges es común, llegando a presentarse en el $80 \%$ de los animales enfermos.

H. parasuis es una bacteria lábil y su aislamiento en cultivo puro puede resultar difícil. Debido a esto, la recuperación del microorganismo a partir de las lesiones macroscópicas o de distintos órganos (si la enfermedad adquiere carácter septicémico) proporciona cierta seguridad de que el aislamiento obtenido se relaciona con la enfermedad (Ferri et al., 2000).
La enfermedad de Glässer constituye hoy en día uno de los problemas más graves de las explotaciones porcinas, sobre todo, de lechones entre cinco a ocho semanas; sin embargo, animales de cualquier edad pueden verse afectados, aún en granjas con altos estándares sanitarios y sin la habitual concurrencia de situaciones de estrés (Ferri et al., 2000).

\section{Reporte de Casos}

Se reporta tres casos de cerdos con signos clínicos sospechosos de enfermedad de Glässer. Los casos se presentaron entre los meses de mayo y junio de 2006. Se analizaron muestras de pulmón procedentes de dos granjas de crianza porcina y de un camal de la zona de Lima. Las muestras fueron procesadas en el Laboratorio de Bacteriología de la Facultad de Medicina Veterinaria, Universidad Nacional Mayor de San Marcos, Lima.

\section{Primer Caso}

Se recibió una muestra de pulmón e hisopado pleural de una cerda de 85 días de edad, de una granja al sur de Lima, la cual fue sometida a necropsia por presentar dificultad respiratoria marcada, cianosis y postración. Otros animales del mismo corral presentaron signos clínicos similares, siendo la enfermedad de curso agudo y desenlace fatal. A la necropsia, se observó una neumonía marcada con focos de hepatización de aspecto brilloso en los lóbulos pulmonares craneoventrales y presencia de abundante fibrina fuertemente adherida a la serosa pulmonar. La muestra de hisopado pleural fue tomada de la pleura parietal, que también presentaba abundante fibrina.

\section{Segundo Caso}

Se recibieron muestras de cuatro pulmones de cerdos de ambos sexos, entre 145 a 150 días de edad, procedentes de un camal de la provincia de Lima, los cuales eran parte del mismo lote de una granja de cerdos que solo se encarga de la etapa de engorde. Las 
Cuadro 1. Características bioquímicas de la bacteria aislada de muestras de pulmones de cerdos

\begin{tabular}{|c|c|c|c|c|c|c|c|c|c|c|c|c|c|}
\hline \multirow[b]{2}{*}{$\begin{array}{l}\text { Pruebas } \\
\text { bioquímicas }\end{array}$} & \multicolumn{2}{|c|}{ Requiere } & \multirow[b]{2}{*}{$\sum_{j}^{f}$} & \multirow[b]{2}{*}{ 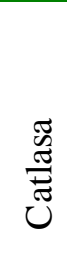 } & \multirow[b]{2}{*}{$\begin{array}{l}\tilde{J} \\
\overrightarrow{\tilde{U}} \\
\stackrel{\vec{x}}{x} \\
0\end{array}$} & \multirow[b]{2}{*}{$\begin{array}{l}\frac{\pi}{\pi} \\
\frac{\pi}{7} \\
\frac{8}{2}\end{array}$} & \multirow[b]{2}{*}{$\overrightarrow{\text { 옵 }}$} & \multirow[b]{2}{*}{ 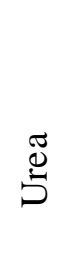 } & \multirow[b]{2}{*}{ 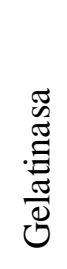 } & \multirow[b]{2}{*}{ 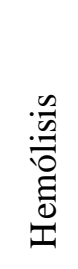 } & \multirow[b]{2}{*}{ 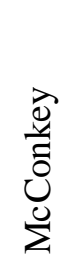 } & \multicolumn{2}{|c|}{ Fermentación } \\
\hline & \begin{tabular}{l}
$>$ \\
$\stackrel{0}{0}$ \\
$\stackrel{0}{0}$ \\
\multicolumn{1}{c}{}
\end{tabular} & 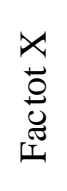 & & & & & & & & & & $\begin{array}{l}\tilde{J} \\
\stackrel{0}{O} \\
\stackrel{\Xi}{0}\end{array}$ & $\begin{array}{l}\tilde{J} \\
\stackrel{0}{0} \\
\widetilde{\sigma}\end{array}$ \\
\hline Pulmón & + & - & - & + & + & - & - & - & - & - & - & + & - \\
\hline $\begin{array}{l}\text { Hisopado } \\
\text { pleural }\end{array}$ & + & - & - & + & + & - & - & - & - & - & - & + & - \\
\hline
\end{tabular}

muestras se tomaron durante el beneficio de los animales. El parénquima pulmonar de los cuatro pulmones presentaba zonas de hepatización con presencia de una capa gruesa de fibrina de color amarillo intenso adherida a la pleura visceral.

\section{Tercer Caso}

Se recibieron muestras de siete pulmones de cerdos de ambos sexos, de 150 días de edad, procedentes de una granja de la provincia de Lima. Las muestras fueron tomadas al momento del beneficio de los animales. No se pudo obtener datos de los síntomas clínicos que presentaron los animales. Los pulmones presentaban diversas lesiones, entre las que destacaban zonas de hepatización, adherencias fibrinosas en pleura parietal y visceral, y aumento marcado de los espacios interalveolares.

\section{Análisis de Laboratorio}

Las muestras fueron cultivadas en agar sangre con una estría de Staphylococcus aureus en condiciones de microaerofilia, y en agar MacConkey e incubadas a $37^{\circ} \mathrm{C}$ por 24 horas. La identificación bacteriana se hizo mediante pruebas bioquímicas de acuerdo a las características bioquímicas de la bacteria y a los resultados de la tinción de Gram.
En todas las muestras cultivadas en agar sangre se observaron colonias a manera de "gotas de rocío" cercanas al crecimiento de Staphylococcus aureus, evidenciándose el típico satelitismo característico de bacterias como $H$. parasuis y A. pleuropneumoniae (Carter, 1989; Williams et al., 2000). No se observó hemólisis en el agar sangre, lo que permitió diferenciarlo de A. pleuropneumoniae (Williams et al., 2000). Por otro lado, no se observó desarrollo bacteriano en las placas de agar McConkey.

En la tinción de Gram, se observó bacilos y cocobacilos pequeños Gram negativos; característica que $H$. parasuis comparte con otros microorganismos como $H$. somnus, $A$. pleuropneumoniae, A. suis, Mannheimia haemolytica, Pasteurella sp. y Bordetella bronchiseptica (Koneman, 1992).

Para la identificación bacteriana se consideró el requerimiento de Factor V (NAD), presencia o ausencia de hemólisis en el agar sangre, prueba de CAMP, presencia de catalasa, oxidasa, hidrólisis de la urea, producción de indol, movilidad y crecimiento en agar Mac Conkey (Carter, 1989; Koneman, 1992; Ferri et al., 2000). Los resultados de los análisis bacteriológicos se muestran en el Cuadro 1. Las características bioquímicas coinciden con las descritas para el $H$. 
parasuis, por lo que se concluyó que el agente patógeno aislado de las muestras fue $H$. parasuis.

Se conoce que Mycoplasma hyopneumoniae es prevalente en los sistemas de crianza de cerdos en la zona de Lima, siendo este microorganismo el agente primario del Complejo Respiratorio Porcino y predisponente a la colonización del tracto respiratorio por otras bacterias concomitantes. Debido a esto, es que la presencia de otros microorganismos que intervienen en la neumonía del cerdo, como $H$. parasuis, adquiere especial importancia debido a la complejidad e intensidad de los problemas respiratorios y enfermedades septicémicas que puede causar la acción concurrente de estos agentes. Además, el aislamiento de $H$. parasuis en sistemas de producción de cerdos bajo crianza intensiva, con adecuados niveles de salud o en núcleos libres de patógenos específicos (SPF) es relevante, ya que irrupciones de este organismo en estos sistemas de crianza pueden causar una alta mortalidad de animales, debido a la ausencia de "memoria inmunológica” contra este agente y por tanto una baja capacidad del sistema inmune para evadir la infección y la colonización bacteriana.

\section{Literatura Citada}

1. Amano H., Shibata M, Kajio $N$, Morozumi T. 1994. Pathologic observations of pigs intranasally inoculated with serovar 1,4 and 5 of Haemophilus parasuis using immunoperoxidase method. J Vet Med Sci 56: 639-644.

2. Bilkei G, Biro O, Bölcskei A, Clavadetscher E, Orban P, Waller C. 1995. Practice related management strategies on postweaning $E$. coli problems in the intensive pig production. Hung Vet J 10: 776-777.
3. Carter GR. 1989. Fundamentos de bacteriología y micología veterinaria. España: Acribia. 304 p.

4. Chang LB. 2003. Identification and differentiation of Haemophilus parasuis sero-nontypeable strains using a species specific PCR and the digestion of PCR products with Hind III endonuclease. In: $34^{\text {th }}$ Annual Meeting American Association of Swine Veterinarians. Florida: AASV. p 299-301.

5. Ferri EFR, Gutiérrez CB, de la Puente VA, García del Blanco N, Navas J, Paniagua C, del Río ML, et al. 2000. Meningitis bacterianas del cerdo: Enfermedad de Glässer. Porci 59: 43-60.

6. Hoefling DC. 1994. The various forms of Haemophilus parasuis. Swine Health Prod 2: 19.

7. Koneman E. 1992. Color atlas and textbook of diagnostic microbiology. $4^{\circ}$ ed. Philadelphia, USA: JB Linppincott. $1154 \mathrm{p}$.

8. Nedbalcova K, Satran P, Jaglic Z, Ondriasova1 R, Kucerova Z. 2006. Haemophilus parasuis and Glässer's disease in pigs: a review. Vet Med-Czech 51(5): 168-179.

9. Nielsen R. 1993. Pathogenicity and immunity studies of Haemophilus parasuis serovars. Acta Vet Scand 34: 193-198.

10. Rapp-Gabrielson VJ, Gabrielson DA. 1992. Prevalence of Haemophilus parasuis serovars among isolates from swine. Am J Vet Res 53: 659-664.

11. Rapp-Gabrielson VJ, Kocur GJ, Clark JT, Muir SK. 1997. Haemophilus parasuis; immunity in swine following vaccination. Vet Med 92: 83-90.

12. Williams J, Torres-León MA, Echeverria-Coello P, Matos-Medina M. 2000. Aislamiento e identificación de Actinobacillus pleuropneumoniae en pulmones de cerdos con pleuroneumonía crónica sacrificados en el rastro municipal de Mérida, Yucatán, México. Rev Biomed 11: 175-181. 